\title{
Cães e gatos abandonados: Uma análise através de notificações e ações do setor de vigilância ambiental no município de Divinópolis, Minas Gerais, Brasil
}

\author{
Abandoned dogs and cats: Notices and actions of the environmental \\ surveillance sector in the municipality of Divinópolis, Minas Gerais, \\ Brazil
}
Bruna Fonseca Rocha ${ }^{1}$, Alysson Rodrigo Fonseca ${ }^{1,2}$, Márcio Henrique Pereira ${ }^{1}$, Cláudio Gonçalves Silva ${ }^{2}$

${ }^{1}$ Universidade do Estado de Minas Gerais - UEMG, Unidade Divinópolis, Minas Gerais, Brasil.
${ }^{2}$ Centro Universitário de Formiga - UNIFOR, Formiga, Minas Gerais, Brasil.
${ }^{3}$ Universidade Federal do Maranhão - UFMA, Campus Universitário de Chapadinha, Maranhão, Brasil.

\section{Resumo}

O abandono de animais domésticos como cães e gatos no Brasil tem se configurado como um hábito comum, ocasionando sérios problemas no âmbito da saúde pública, da economia e do bem-estar animal. O presente artigo teve como objetivo fazer uma análise sobre a causa e destino desses animais no município de Divinópolis - MG, a partir de notificações do Setor de Vigilância Ambiental do município. O trabalho foi executado por meio de pesquisa documental nas fichas desse setor, alusivas aos anos de 2011 e 2012, referentes às ocorrências geradas por cães e gatos. Os dados obtidos foram computados e organizados em planilhas do programa Microsoft Excel. Nos dois anos estudados, registraram-se 3.836 ocorrências para cães e gatos, 3.628 para os caninos e 208 para os felinos. Observou-se que as maiores porcentagens de notificações foram registradas para os cães, destacou-se a categoria "Cães Doentes" $(38 \%, \mathrm{n}=1360)$, seguido por "Cães Abandonados" (17\%, $\mathrm{n}=620)$, que contabilizam juntas 55\% do número total de registros $(\mathrm{n}=1995)$. No que se refere aos gatos, verificou-se um maior número de notificações para a categoria "Recolhimento de Ninhada" com $43 \%$ dos dados $(n=89)$, seguido por "Gato Doente" (19\%, n = 40) e "Gato Abandonado" (17\%, $\mathrm{n}=35)$, o que contabiliza 79\% dos registros $(\mathrm{n}=164)$. Os resultados evidenciaram a relevância do problema referente a cães e gatos abandonados em Divinópolis - MG, as medidas executadas pelo setor de Vigilância Ambiental são fundamentais para o controle e minimização dessa situação.

Palavras-chave: Animais Domésticos; Zoonoses; Saúde Pública. 


\section{Abstract}

The abandonment of pets such as dogs and cats in Brazil has been characterized as a common habit, bringing about serious problems in the field of public health, economics and animal welfare. The current article aims to do a survey of those animals in the municipality of Divinópolis - MG from notifications of the Town's Environmental Surveillance Sector. The work was conducted through the documental research in the cards of that sector in the years of 2011 and 2012, concerning the incidents generated by both dogs and cats. The data obtained were computed and organized in spreadsheet of Microsoft Excel program. In the years of 2011 and 2012, 3,836 incidents for dogs and cats were recorded, in that case, 3,628 being for dogs and 208for cats. It was found that the greatest percentages of incidents were recorded for dogs, stressing the "Sick Dogs" category (38\%, $n=1378)$, followed by "Abandoned Dogs" $(17 \%, n=617)$, which accounted together for 55\% of the total number of records $(n=1995)$. As far as the cats are concerned, an increased number of incidents for the "Cat Litter Gathering" with $43 \%$ of the data $(n=89)$, followed by "Sick Cat" $(19 \%, n=40)$ and "Abandoned Cat" $(17 \%, n=35)$, which accounts for a total percentage of $79 \%$ of the records $(n=164)$. The results stood out the relevance of the situation concerning both cats and dogs abandoned in Divinópolis - MG, the measures being executed by the Environmental Surveillance sector fundamental to the control and minimization of the problem.

Keywords: Domestic Animals; Zoonoses; Public Health.

\section{Introdução}

O crescimento excessivo das populações de cães e gatos de rua tem sido um grande problema nas áreas rurais e urbanas dos municípios brasileiros. Nesse contexto, $60 \%$ dos domicílios possuem, pelo menos, um animal de estimação, o que representa 32 milhões de cães e cerca de 16 milhões de gatos domiciliados ${ }^{1}$. Entretanto, junto ao número de animais de estimação, tem crescido o número de animais encontrados em situação de abandono nas ruas, embora essa prática seja crime previsto pela Lei Federal $n^{\circ}$ 9605/98².

Geralmente, o fenômeno dos cães e gatos abandonados nas cidades ocorre em função da falta de conhecimento e de responsabilidade da população em relação ao problema, da omissão do poder público frente ao problema e, ainda, da verticalização da cidade, pois a grande maioria dos condomínios de apartamentos não permite a presença de cães e gatos, o que, em muitas vezes, faz com que os donos os abandonem ${ }^{3}$.

Cães e gatos, quando abandonados e vivendo nas ruas, podem causar acidentes de trânsito, acúmulo de dejetos, ruídos (latidos, uivos e miados) e excreções nas ruas e passeios (fezes e urina), dispersão de lixo e danos a propriedades públicas e privadas ${ }^{4}$. Além disso, quando não adequadamente tratados, vacinados e vermifugados, podem constituir-se em ameaça para a saúde pública, já que podem transmitir vários tipos de doenças, como a raiva ${ }^{5}$, leishmanioses ${ }^{6-7}$, toxocaríase ${ }^{8}$, toxoplasmose $\mathrm{e}^{9-10}$ e outras doenças parasitarias ${ }^{11-12}$, além das implicações envolvidas com os casos de agressão aos humanos e a outros animais ${ }^{13}$. Segundo Ciampo et al. ${ }^{13}$, Macedo e Rosa ${ }^{14}$ (2004) e Palacio et al. ${ }^{15}$, as mordeduras caninas aumentam o risco de transmissão de zoonoses e são consideradas causa importante de morbidade e mortalidade, o que compromete tanto a integridade física como a psicológica das vitimas.

No município de Divinópolis, o Setor de Vigilância Ambiental é o órgão responsável no que se refere aos agravos e doenças transmitidas por animais (zoonoses), e atua por meio do controle de populações de animais domésticos (cães e gatos) e de populações de animais sinantrópicos, como morcegos, pombos, ratos, mosquitos, pulgas, carrapatos, abelhas e outros. Todas as ações desenvolvidas por esse Setor são arquivadas em forma de fichas em um banco de dados. Tal arquivo torna-se uma fonte relevante de dados, pois permite identificar, em função do tempo (sazonalidade) e local, as principais regiões de ocorrência de organismos, o que permite o mapeamento da ocorrência das pragas urbanas no município.

A partir desse contexto, este estudo buscou realizar o levantamento da ocorrência de cães e gatos abandonados no município de Divinópolis - MG, com base no arquivo do Setor de Vigilância Ambiental do município, identificando a natureza das ocorrências, as regiões, os principais motivos que geraram a solicitação de intervenção e ainda, as ações desencadeadas para minimizar ou solucionar o problema.

\section{Metodologia}

O município de Divinópolis - MG, foco deste estudo, encontra-se localizado na região centro-oeste de Minas Gerais e possui uma área de $716 \mathrm{~km}^{2}$, equivalente a $0,12 \%$ da área do Estado. A sede do município situa-se na interseção das coordenadas geográficas $20^{\circ} 8^{\prime} 21^{\prime \prime}$ de latitude Sul e 4453'17' de longitude Oeste, a 718 metros acima do nível do mar. 
Atualmente, conta com uma população de 216.099 habitantes. O clima é do tipo subtropical, com índice pluviométrico anual entre 1.100 e $1.700 \mathrm{~mm}$. A temperatura média de inverno é de $16^{\circ} \mathrm{C}$ e de verão em torno dos $25^{\circ} \mathrm{C}$. O domínio fitogeográfico onde se insere o município é de cerrado, já bastante alterado pelo processo de metropolização, são raras áreas com vegetação natural ${ }^{16-17}$.

O trabalho foi realizado por meio de pesquisa documental nas fichas do Setor de Vigilância Ambiental, alusivas aos anos de 2011 e 2012, referentes às ocorrências geradas por cães e gatos. Nessas fichas, encontram-se informações referentes à identificação do animal (no caso, cão ou gato), o problema verificado e, ainda, o local de ocorrência e data (mês/ano). Informações complementares relativas às ações desencadeadas em relação à ocorrência foram obtidas junto ao Setor de Controle de Zoonoses do município. Os dados foram organizados em planilhas do programa Microsoft Excel ${ }^{\circledR}$ para cálculos de frequência e formação de tabelas e gráficos.

\section{Resultados e discussão}

Nos anos de 2011 e 2012, foram registradas 3.628 ocorrências caninas e 208 felinas, totalizando 3.836 ocorrências nos dois anos. Os registros das ocorrências foram categorizados em função de cada situação descrita nas fichas, foram geradas para os cães 11 categorias: cadela no cio, cadela prenhe, cão abandonado, cão atropelado, cão doente, cão ferido, suspeita de leishmaniose, leishmaniose positiva, eutanásia, pedido de castração e por fim, recolhimento de ninhada. Já os registros para os gatos geraram sete categorias: gata prenhe, gato abandonado, gato doente, gato ferido, pedido de castração, eutanásia e recolhimento de ninhada.

A Figura 1 mostra, para os cães, as categorias que geraram as fichas, ou seja, o problema registrado pelos técnicos do setor de Zoonoses, seguido pelo número de ocorrências.

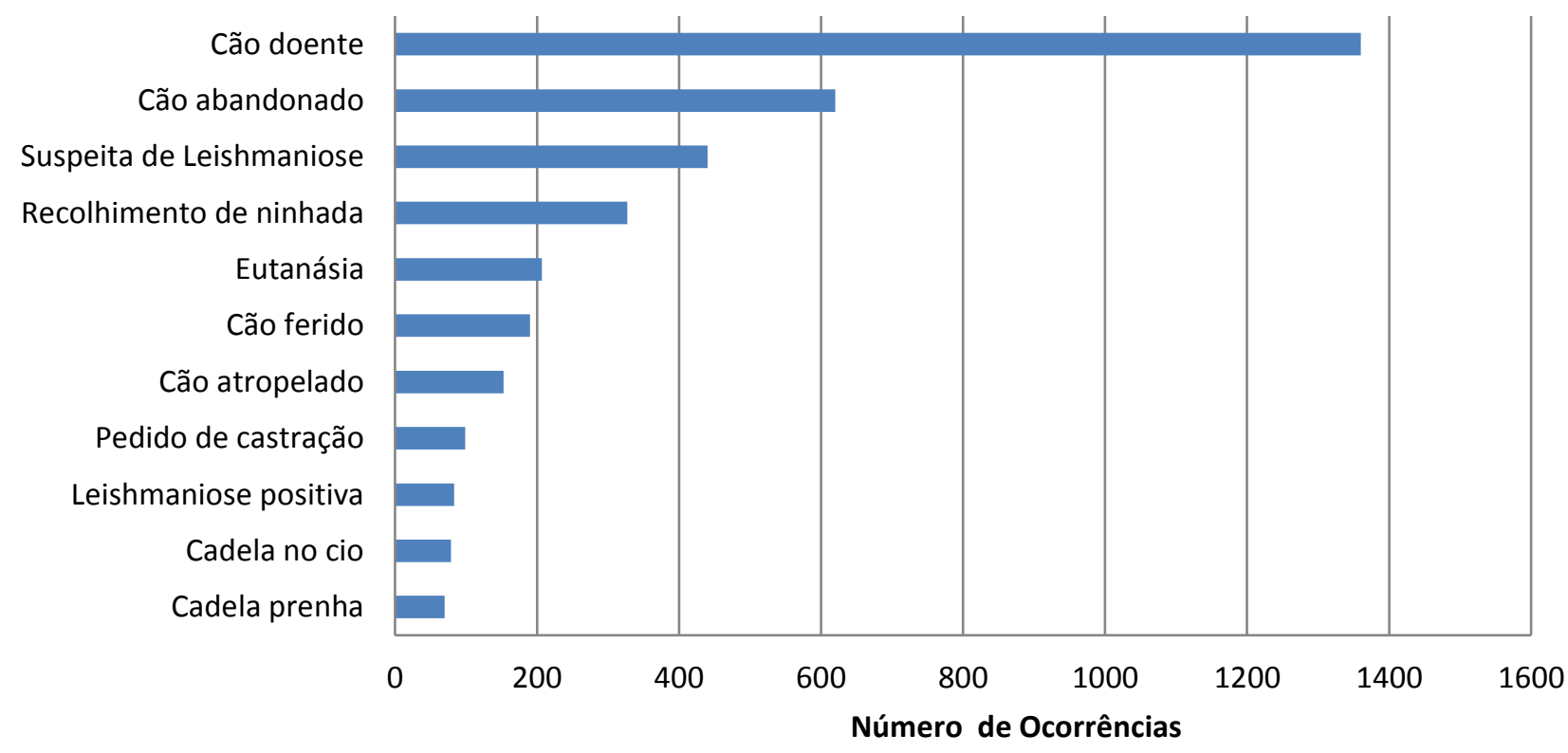

Figura 1. Ocorrências caninas registradas pelo do Setor de Vigilância Ambiental no município de Divinópolis - MG, nos anos 2011 e 2012.

Os resultados obtidos mostraram maior porcentagem de notificações relacionadas a "cães doentes" (38\%) e "cães abandonados" (17\%), que contabilizaram juntos um total de 1980 registos (55\%). De acordo com Carneiro ${ }^{18}$ e Gomes ${ }^{19}$, após uma situação de abandono, cães e gatos ficam expostos a patógenos, vetores e fatores climáticos, tornando-se mais vulneráveis a doenças e parasitas, podendo assim constituir-se como reservatório de doenças e possíveis transmissores. Os resultados mostram que a população parece reconhecer esse perigo em potencial, buscando o setor de vigilância ambiental e solicitando a resolução do problema.
A Figura 2 mostra as ocorrências e categorias geradas pelos gatos. Verificou-se um maior número de ocorrências para a categoria "recolhimento de ninhada", com 89 registros e $43 \%$ de representatividade. Os gatos, em consequência de sua aptidão em escalar muros e telhados, têm o hábito de fazer seus ninhos em áreas privadas, como telhados, forros, lajes e quintais de residências. Esse fato ocasiona transtornos aos proprietários, que acabam por buscar a ajuda do setor de Vigilância Ambiental. 


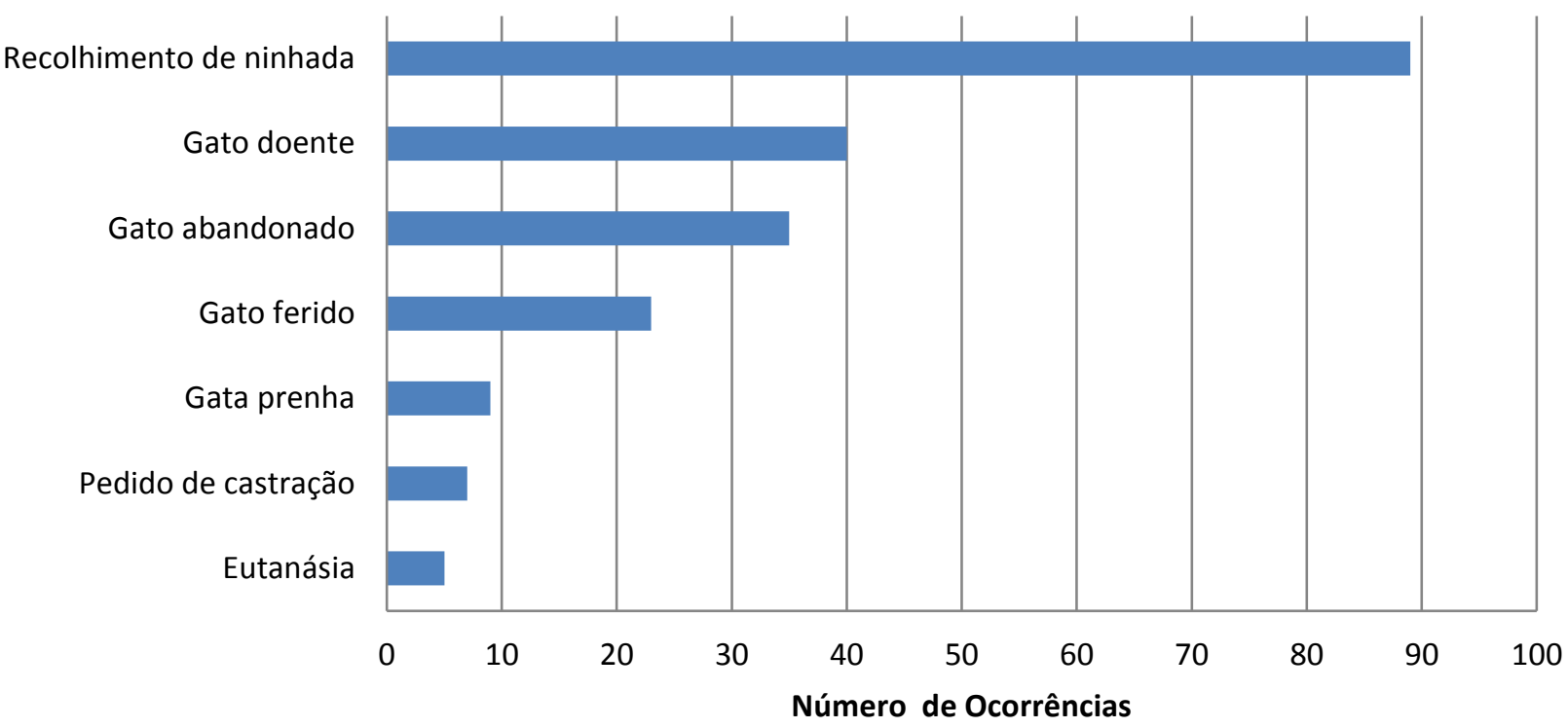

Figura 2. Comparativo de ocorrências de felinos registradas pelo do Setor de Zoonoses no município de Divinópolis MG, nos anos 2011 e 2012.

De acordo com o setor de Vigilância Ambiental de Divinópolis-MG, em função de cada tipo de categoria (ou situação) registrada para os cães e gatos, são geradas ações específicas, na maioria das vezes aplicadas tanto em relação aos caninos, quando aos felinos. Dessa forma, no caso de cães ou gatos, "doentes" ou "feridos" ocorre o recolhimento do animal, que é direcionado ao Centro de Referência de Vigilância em Saúde Ambiental - CREVISA, onde o animal recebe os cuidados básicos, faz o exame para Leishmaniose (no caso de cães), é castrado e, por fim, devolvido ao local onde foi recolhido, pode, também, ser encaminhado para doação. Em casos mais graves de doenças ou ferimentos, o animal é encaminhado para a eutanásia.

No caso de cadela ou gata no cio, procede-se o recolhimento do animal com a posterior castração. Quando se trata de um animal de rua, após a castração, esse fica de sete a oito dias no CREVISA para sua recuperação. Cabe ressaltar que esse Centro tem uma equipe de veterinários que atendem gratuitamente à população. No caso de atendimentos particulares, são realizadas, em média seis castrações de animais por dia, $80 \%$ destes referem-se a cães. Nesse caso, o animal é castrado e devolvido ao dono no mesmo dia. Segundo Catapan et al. ${ }^{20}$, a castração é um procedimento cirúrgico de baixo risco, de recuperação rápida, e pós-operatório simples, que pode ser utilizada como uma profilaxia eficaz quando se trata de conter o crescimento desordenado desses animais. Além disso, tal procedimento reduz a suscetibilidade a várias doenças. De acordo com Soto et al. ${ }^{21}$, embora esse método cirúrgico seja descrito como a principal intervenção de controle populacional canino, são poucos os trabalhos que mostram sua efetividade como método isolado de controle.
No que se refere à "cadela" ou "gata prenha", o animal é recolhido e castrado, com o descarte fetal. Após a recuperação, o animal é devolvido ao local onde foi capturado ou é encaminhado para adoção. No caso de "recolhimento de ninhada", os filhotes são recolhidos junto à mãe, vermifugados e encaminhados para adoção. A progenitora é castrada e também liberada no local onde foi recolhida. Segundo a Secretaria do Estado de Saúde de São Paulo $^{22}$, as cadelas e gatas são animais pluríparos de gestação curta, com grande potencial de produção de proles numerosas que podem atingir a maturidade sexual a partir de seis meses de idade, o que evidencia um elevado potencial de crescimento populacional em médio e longo prazo.

Em cães, quando se tem a "suspeita de leishmaniose", é feito um teste rápido, o Dual Parth Platform - DPP ou Plataforma de Duplo Compartilhamento (TR-DPP ${ }^{\circledR}$ BioManguinhos/Fiocruz) que quando positivo, é encaminhado para o exame clínico confirmatório Enzyme Linked Immunosorbent Assay (BioManguinhos/Fiocruz). Quando não confirmada a doença, faz-se o tratamento do animal, a castração e a devolução ao local onde foi encontrado ou ao dono do animal, quando o pedido é particular. No caso da confirmação da doença, procede-se à eutanásia do animal.

No município de Divinópolis - MG, as Leishmanioses têm se constituído em um sério problema de saúde pública. O cão doméstico é o principal reservatório da doença, que tem como vetor dípteros da Família Psychodidae, comumente conhecidos como mosquito palha ou birigui ${ }^{6,22}$. Em Divinópolis-MG, ambas as formas da doença (visceral e tegumentar) se encontram em expansão, tendo-se 
registro de 135 casos da forma tegumentar no período entre 1990 e 1999 e 54 casos entre os anos 2007 e $2013^{24-25}$.

Para cães e gatos "abandonados", faz-se o recolhimento do animal, tratamento (quando necessário) e castração, com a posterior devolução ao local onde foi capturado. No caso de filhotes, estes são também vermifugados e direcionados para a adoção. O abandono de animais é frequente e comum, e causa prejuízos nos âmbitos da saúde pública, social, ecológica, economia e do bem-estar animal ${ }^{26}$. As adoções, provenientes de animais que se encontram na CREVISA, ocorrem quinzenalmente nos finais de semana, em feiras que acontecem em bairros da cidade.

No caso de cães atropelados, faz-se uma avaliação do animal, seguido pelo tratamento, castração e soltura. Quando o animal está gravemente ferido, sem perspectivas de sobrevivência, é realizada

\section{MIXICIPIO DE DINTÓPOLIS}

REGIOES DE PLANEJAMENTO

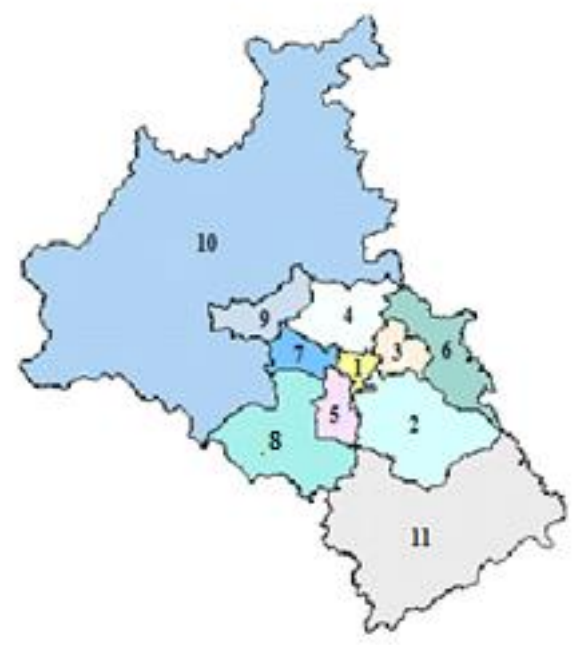

a eutanásia. Caber ressaltar que a eutanásia é realizada em casos de leishmaniose positiva, ferimentos graves, doenças infectocontagiosas, tumores malignos e no caso de animais agressivos e perigosos. A eutanásia é a morte provocada de maneira humanitária e misericordiosa de animais, executada por pessoas especialmente treinadas ${ }^{27}$, sob a responsabilidade de um médico veterinário, em ambiente tranquilo e adequado, de acordo com a Resolução $714^{28}$ do Conselho Federal de Medicina Veterinária. O procedimento utiliza barbitúricos, anestésicos inaláveis, $\mathrm{CO}^{2}, \mathrm{CO}$ e cloreto de potássio com anestesia geral prévia. Em cães, pode-se ainda utilizar a eletrocussão com sedação prévia ${ }^{28}$.

No total dos 3.836 registros obtidos para cães e gatos, 3.807 apresentaram-se distribuídos entre as 11 regiões de planejamento do município (Figura 3). Desses registros, 29 fichas não identificavam a região da ocorrência, não foram, portanto, contabilizadas.

\section{OCORRÊCLAS}

\begin{tabular}{|c|c|c|c|}
\hline & & CÃES & GATOS \\
\hline 1 & CENTRAL & 369 & 32 \\
\hline 2 & StDESTE & 789 & 37 \\
\hline 3 & NORDESTE & 530 & 26 \\
\hline 4 & NOROESTE & 598 & 34 \\
\hline 5 & SUDOESTE & 534 & 42 \\
\hline 6 & NORDESTE DISTAVTE & 206 & 09 \\
\hline 7. & oEsTE & 195 & 15 \\
\hline 8 & StDOESTE DISTAYTE & 222 & 08 \\
\hline 9 & I NOROESTE DISTANTE & 93 & 01 \\
\hline 10 & ZONA RURAL NOROESTE & 17 & - \\
\hline II & ZONA RTR.AL STDESTE & 46 & 04 \\
\hline
\end{tabular}

Figura 3. Distribuição geográfica de ocorrências caninas e felinas registradas no município de Divinópolis, MG, nos anos 2011 e 2012.

No que se refere aos cães (Figura 3), as regiões que apresentaram maior índice de ocorrências foram a Central (1) e as limítrofes (2, 3, 4 e 5), contabilizando $77,72 \%$ das notificações $(n=2.820)$. Dentre estas, as regiões com maior número de registros foram a sudeste $(n=789)$ e noroeste $(n=598)$, totalizando $38,26 \%$ das ocorrências. No que concerne aos felinos, o maior valor de ocorrências está conferido à região Sudoeste (5) com 42 registros, seguido pelas regiões Sudeste (2), Noroeste (4) e Central (1), com 37, 34 e 32 registros, respectivamente. As quatro juntas somam 145 ocorrências, equivalentes a $69,71 \%$ do total de registros. De forma semelhante aos cães, o maior número de registros foi verificado para a região central e as limítrofes. A maior concentração das ocorrências nessas regiões certamente está relacionada ao maior índice de urbanização, que propicia maior oferta de alimentos e abrigos para os animais, além do que há pessoas que tratam dos animais abandonados, ofertando-lhes alimento e água.

\section{Considerações Finais}

Os resultados mostrados aqui evidenciam um problema que afeta a população das cidades e expõe cães e gatos abandonados a uma série de sofrimentos, os quais podem ser evitados por intervenção de uma política de recolhimento e destinação adequada, aliada ao controle populacional por meio da castração e, ainda, de medidas de educação ambiental que visem a conscientizar as pessoas em relação aos problemas gerados pelas zoonoses e pelo abandono desses animais. Para se obter êxito nessas ações, torna-se fundamental a participação comunitária de órgãos 
públicos e privados, de forma a englobar todos os interessados, em ação conjunta de toda a sociedade.

\section{Declaração de conflitos de interesses}

Os autores do artigo afirmam que não houve nenhuma situação de conflito de interesse, tais como propostas de financiamento, emissão de pareceres, promoções ou participação em comitês consultivos ou diretivos, entre outras, que pudessem influenciar no desenvolvimento do trabalho.

\section{Agradecimentos}

À FAPEMIG - Fundação de Amparo à Pesquisa do Estado de Minas Gerais, pela disponibilização de Bolsa de Iniciação Científica - BIC e à Secretaria de Saúde do Município de Divinópolis - MG, pelo acesso às informações e registros.

\section{Referências}

1. DOMINGUES, L. R. Posse responsável de cães e gatos na área urbana do município de Pelotas, RS, Brasil. $87 \mathrm{f}$. Dissertação (Mestrado em Medicina) - Universidade Federal de Pelotas, Pelotas, 2012.

2. BRASIL, LEI No 9.605, de 12 de fevereiro de 1998. Dispõe sobre as sanções penais e administrativas derivadas de condutas e atividades lesivas ao meio ambiente. Disponível em http://www.planalto.gov.br/ccivil_03/leis/L9605.htm>. Acesso em: 30 mar. 2017.

3. SANTANA, L. R.; MARQUES, M. R. Maus tratos e crueldade contra animais nos Centos de Controle de Zoonoses: aspectos jurídicos e legitimidade ativa do Ministério Público para propor Ação Civil Pública. Artigo Disponível em: <http://www.Fórumnacional.com.br/maus_tratos_CCz_de_ Salvador. pdf, 2001>. Acesso em: 02 mar. 2015.

4. STAFFORD, K. The Welfare of Dogs. The Netherlands: Springer. 2007. UNESCO. Declaração dos direitos dos animais, de 27 de janeiro de 1978. Disponível em: http://www.forumnacional.com.br/declaracao_universal_do s_direitos_dos_animais.pdf. Acesso em: 13 de mar. 2012

5. CEDIEL N.; HOZ, F.; VILLAMIL, L.C.; ROMERO J.; DIAZ, A. Epidemiología de la rabia canina en Colombia. Revista Salud Pública, v. 12, n. 3, p. 368-379. 2010.

6. MARGONARI, C.; SOARES, R. P.; ANDRADE-FILHO, J. D.; XAVIER , D. C.; SARAIVA, L.; FONSECA , A. L.; SILVA , R. A.; OLIVEIRA , M. E.; BORGES , E. C.; SANGUINETTE, C. C.; MELO, M. N. Phlebotomines and flies (Diptera: Psychodidae) and Leishmania infection in Gafanhoto Park, Divinópolis, Brazil. Journal of Medical Entomology, v. 47, n. 6, p. 1212-1219, 2010.

7. ORTIZ, R. C.; ANVERSA, L. Epidemiologia da leishmaniose visceral em Bauru, São Paulo, no período de 2004 a 2012: um estudo descritivo. Epidemiologia e Serviços de Saúde, v. 24, n. 1, p. 97-104, 2015.

8. MARTINEZ, I.; GUTIERREZ, M.; RUIZ, L.A.; GUTIERREZ, E.M.; SOSA, A.A.; VALENCIA, J.L.; GAONA, E. Prevalence of anti - T. canis antibodies in stray dogs in Mexico City. Veterinary Parasitology, v. 153, n. 13, p. 270-276, 2008.

9. GALVÃO, A. L. B.; VACONCELlOS, A. L.; NAVARRO, I. T.; BRESCIANI, K. D. S. Aspectos da toxoplasmose na clínica de pequenos animais. Semina: Ciências Agrárias, v. 35, n. 1, p. 393-410, 2014.
10. ROCHA, E. M.; NUNES, A. A.; FLAUSINO, W.; ROCHA, M. N. M.; SOUZA, W. J., LOPES, C. W. G. Cats and dogs as risk factors for pregnant women on Toxoplasma gondii infection at the region of Araguarina in the state of Tocantins, Brazil. Revista Brasileira Medicina Veterinária, v. 34, n. 2, p.79-82, 2012.

11. POLO, L.J.; CORTÉS, J.A.; VILLAMIL, L.C.; PRIETO, E. Contaminación de los Parques Públicos de la Localidad de Suba, Bogotá con Nemátodos Zoonóticos. Revista Salud Pública, v. 9, n.4 p. 550-557, 2007.

12. MUNDIM, M.J.S.; ROSA, L.A.G.; HORTÊNCIO, S.M.; FARIA, E.S.M.; RODRIGUES, R.M.; CURY, M.C. Prevalence of Giardia duodenalis and Cryptosporidium spp. in dogs from different living conditions in Uberlândia, Brazil. Veterinary Parasitology, v. 144, n. 3-4, p. 356-359, 2007.

13. CIAMPO, L.A.; RICCO, R.G.; ALMEIDA, C.A.; BONILHA, L.R.; SANTOS, T.C. Acidentes de mordeduras de cães na infância. Revista de Saúde Pública, v. 34, n. 4 p. 411-412, 2000.

14. MACEDO, J.L; ROSA, S.C.; Reconstrução de couro cabeludo após mordedura canina. Revista do Colégio Brasileiro de Cirurgiões. v. 31, n. 1, p. 27-33, 2004.

15. PALACIO, J.; LEÓN, M.; GARCIA, S. Aspectos epidemiológicos de las mordeduras caninas. Gaceta Sanitária, v. 19, n. 1, 2005.

16. SEPLAN. Secretaria Municipal de Planejamento de Divinópolis. Anuário estatístico de Divinópolis 2004. Divinópolis: SEPLAN/PMD, 2004.

17. IBGE -Instituto Brasileiro de Geografia e Estatística. Atlas do Censo Demográfico 2010. Rio de Janeiro: IBGE. Disponível em: <http://www.ibge.gov.br/cidadesat/link. php?uf=mg >. Acesso em 28 de ago. 2016.

18. CARNEIRO, G. R. Os invisíveis: animais de tração e o abandono de cães e gatos em Campina Grande. $35 f$. Trabalho de Conclusão de Curso (Graduação em Comunicação Social) - Universidade Estadual da Paraíba, Centro de Ciências Sociais Aplicadas, 2011.

19. GOMES, C. C. M. Guarda responsável de animais de companhia: um estudo sobre a responsabilidade civil dos proprietários e a entrega de cães e gatos na Diretoria de Vigilância Ambiental do Distrito Federal. 70 f., Monografia (Bacharelado em Medicina Veterinária) Universidade de Brasília, Brasília, 2013.

20. CATAPAN, D. C.; DA COSTA, E. D.; DA CUNHA, G. R.; PIMPÃO, C. T. Impacto do programa de esterilização cirúrgica na população de cães e gatos do município de São José dos Pinhais-PR. Revista Brasileira de Ciência Veterinária, v. 21, n. 3, p. 178-182. 2014.

21. SOTO, F.R.M.; SOUSA, A.J.; AZEVEDO, S.S. Experiência do município de Ibiúna-SP no controle populacional de cães. Pubvet, v. 2, n. 28, p. 1982-1985, 2008.

22. SES-SP. Secretaria de Estado da Saúde de São Paulo. Programa de Controle de Populações de Cães e Gatos do Estado de São Paulo. São Paulo, 2009.

23. JUNIOR, C. C.; LUCCI, J.; LOPES, E.; ROSA, M.; BARBIERI, J.; ROCHA, C. Frequência de cães soropositivos para leishmaniose visceral canina em Divinópolis - MG em 2010. Ars Veterinaria, v. 29, n. 4, p. 72-72, 2013.

24. SINAN. Sistema de Informação de Agravos de Notificação - Brasília: Leishmaniose: casos confirmados notificados no Sistema de Informação de Agravos de 


\section{Notificação.}

Disponível

em:<http://dtr2004.saude.gov.br/sinanweb/index.

php?name $=$ Tnet $>$. Acesso em: 20 out. 2014.

25. NASCIMENTO, B. W. L.; SARAIVA, L.; NETO, R. G. T.; MEIRA, P. C. L. S.; SANGUINETTE, C. C.; TONELLI, G. B.; BOTELHO, H. A.; BELO, V. S.; SILVA, E. S.; GONTIJO, C. M. F.; FILHO, J. D. A. Study of sand flies (Diptera: Psychodidade) in visceral and cutaneous leishmaniasis areas in central western of Minas Gerais StateBrazil. Acta Tropical, v. 125, n. 3, p. 262-268, 2013.

26. ALVES, A. J. S.; GUILLOUX, A. G. A.; ZETUN, C. B.; POLO, G.; BRAGA, G. B.; PANACHÃO, L. I.; SANTOS, O.; DIAS, R. A. Abandono de cães na América Latina: revisão de literatura. Revista de Educação Continuada em Medicina Veterinária e Zootecnia, v. 11, n. 2, p. 35-41, 2013.

27. HATCH, R. C. Agentes usados para eutanásia. In: BOOTH, N. H.; McDONALD, L. E. Farmacologia e Terapêutica em medicina veterinária. 6.ed. Rio de Janeiro: Guanabara Koogan, 1992. p. 928-932.

28. CFMV- Conselho Federal de Medicina Veterinária. Resolução $\mathrm{n}^{\circ} 714$ de 20 de junho de 2002. Dispõe sobre procedimentos e métodos de eutanásia em animais, e dá outras providências. Diário Oficial [da] Republica Federativa do Brasil, Brasília, 21 jun. 2002. 